\title{
Deep Eutectic Solvent-Functionalized Mesoporous Silica SBA-15-Based Mixed Matrix Polymeric Membranes for Mitigation of $\mathrm{CO}_{2}{ }^{\dagger}$
}

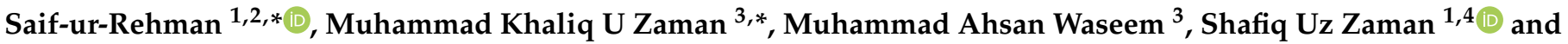 \\ Muhammad Shozab Mehdi ${ }^{4}$
}

check for

updates

Citation: Saif-ur-Rehman; Zaman, M.K.U.; Ahsan Waseem, M.; Zaman, S.U.; Shozab Mehdi, M. Deep Eutectic Solvent-Functionalized Mesoporous Silica SBA-15-Based Mixed Matrix Polymeric Membranes for Mitigation of $\mathrm{CO}_{2}$. Eng. Proc. 2021, 12, 61. https://doi.org/10.3390/ engproc2021012061

Academic Editor: Muhammad Tanveer

Published: 12 January 2022

Publisher's Note: MDPI stays neutral with regard to jurisdictional claims in published maps and institutional affiliations.

Copyright: (C) 2022 by the authors. Licensee MDPI, Basel, Switzerland. This article is an open access article distributed under the terms and conditions of the Creative Commons Attribution (CC BY) license (https:// creativecommons.org/licenses/by/ $4.0 /)$.
1 Department of Chemical Engineering, COMSATS University Islamabad, Lahore Campus, Defence Road, Off Raiwind Road, Lahore 54000, Pakistan; shafiqzaman029@gmail.com

2 Interdisciplinary Research Center of Biomedical Materials (IRCBM), COMSATS University Islamabad, Lahore Campus, Defence Road, Off Raiwind Road, Lahore 54000, Pakistan

3 Department of Chemical Engineering, University of Gujrat, Jalalpur Jattan Road, Gujrat, Punjab 50700, Pakistan; ahsanwaseem@uog.edu.pk

4 Department of Chemical Engineering, Ghulam Ishaq Khan Institute of Engineering Sciences and Technology, Topi 23640, Khyber Pakhtunkhwa, Pakistan; shozab@giki.edu.pk

* Correspondence: saifzciit@gmail.com (S.-u.-R.); khaliqzaman@uog.edu.pk (M.K.U.Z.)

$\dagger$ Presented at the 1st International Conference on Energy, Power and Environment, Gujrat, Pakistan, 11-12 November 2021.

Abstract: In this research, a novel DES (choline chloride + decanoic acid) was synthesized, and SBA-15 was functionalized by the DES to form a DES-SBA filler to fabricate MMMs. DES-SBA-based MMMs at $5 \%, 10 \%, 15 \%$, and 20\% were synthesized and evaluated. The DES-SBA-based MMMs were characterized by scanning electron microscopy (SEM) and Fourier transform infrared spectroscopy (FTIR). Gas permeation tests were applied to the pure and mixed gas samples, and the results of the permeability and selectivity $\left(\mathrm{CO}_{2} / \mathrm{CH}_{4}\right.$, and $\left.\mathrm{CO}_{2} / \mathrm{N}_{2}\right)$ of the membranes are reported. DES modification of SBA-15 increased the efficiency of the synthesized MMMs in comparison with the pristine polysulfone membrane.

Keywords: SBA-15; deep eutectic solvent; carbon dioxide; permeability; selectivity

\section{Introduction}

Human outputs have contributed to releasing a significant amount of carbon dioxide $\left(\mathrm{CO}_{2}\right)$ gas into the climate, which is the major cause of global warming and air pollution [1].The typical sources of $\mathrm{CO}_{2}$ emission include combustion of fossil fuels, natural gas streams, products of coal gasification, and biogas synthesis from anaerobic digestion [2]. As a result, it has turned out to be a big challenge for humankind to reduce $\mathrm{CO}_{2}$ in the biosphere [3]. The major challenge faced on an industrial scale is the removal of harmful gases or contaminants from mixtures of several gases [4]. The most employed industrial techniques used for said purpose include pressure swing adsorption, chemical absorption by means of reactive solvents, and cryogenic separation [5], but these techniques involve considerably high capital costs and complex apparatus and consume large amounts of energy as compared to membranes [2].

In this study, a deep eutectic solvent was synthesized by mixing choline chloride with decanoic acid to modify SBA-15. This combination was used due to the amine and carboxyl groups of choline chloride and decanoic acid, respectively. The modified material, that is, the combination of hybrid materials of organic and inorganic compounds, was used as a filler and Polysulfone was used as a polymeric support in MMMs. The MMMs of different compositions were synthesized and evaluated by a gas permeation analyzer, and 
the incorporation of DES-functionalized SBA-15 was proven to be better filler in MMMs for mitigation of $\mathrm{CO}_{2}$ from gaseous mixtures.

\section{Methods}

\subsection{Synthesis of $S B A-15$}

SBA-15 was synthesized according to a previously reported method [6]. In short, $12 \mathrm{~mL}$ DI water was used to dissolve $2 \mathrm{~g}$ Pluronic $\mathrm{P}_{123}$ at $40^{\circ} \mathrm{C}$, and then $60 \mathrm{~mL}$ of $2 \mathrm{M} \mathrm{HCl}$ was added to it and agitated for $3 \mathrm{~h}$. The mixture was placed in a Teflon-lined hydrothermal autoclave for $24 \mathrm{~h}$ at $100{ }^{\circ} \mathrm{C}$. The product was filtered and washed using DI water and dried at room temperature. The calcinations of the yield were performed for $6 \mathrm{~h}$ at $600{ }^{\circ} \mathrm{C}[7,8]$.

\subsection{Synthesis of Deep Eutectic Solvent}

The DES was synthesized by mixing choline chloride, i.e., HBA, and decanoic acid, i.e., $\mathrm{HBD}$, in a round-bottom flask at $80{ }^{\circ} \mathrm{C}$ for $3 \mathrm{~h}$ with continuous agitation using a magnetic stirrer at $100 \mathrm{rpm}$. Equal amounts (1:1) of both components were used by mass to form a homogeneous composition of the DES $[9,10]$.

\subsection{Functionalization of $S B A-15$ by DES}

The synthesized SBA-15 was functionalized by the synthesized DES using a solvent evaporation technique. The SBA-15 and choline chloride/decanoic acid-based DES was mixed with ethanol at $8: 1$ by mass and subjected to vigorous mixing for $6 \mathrm{~h}$. The mixture was dried at room temperature for $24 \mathrm{~h}$ until complete evaporation of the ethanol. The dried particles of the synthesized DES-functionalized SBA-15 were named DES-SBA [11].

\subsection{Synthesis of Mixed Matrix Membranes}

The membranes were formulated using the compositions presentedin Table 1. Tetrahydrofuran (THF) and polysulfone were mixed first and then the DES-SBA filler was added. The mixing took place at $350 \mathrm{rpm}$ for $24 \mathrm{~h}$ at $35^{\circ} \mathrm{C}$ to obtain a uniform mixture. The homogeneous mixture was placed in a flat-bottom Petridish and covered with an inverted funnel for another $24 \mathrm{~h}$ to synthesize dried MMMs [11].

Table 1. Composition of MMMs.

\begin{tabular}{ccccc}
\hline Membrane & Composition & PSF & DES-SBA & THF \\
\hline DS-0 & PSF & 4.8 & - & 95.2 \\
\hline DS-1 & DES-SBA 5\% & 4.8 & 0.238 & 94.962 \\
\hline DS-2 & DES-SBA 10 $\%$ & 4.8 & 0.476 & 94.724 \\
\hline DS-3 & DES-SBA 15\% & 4.8 & 0.714 & 94.486 \\
\hline DS-4 & DES-SBA 20 $\%$ & 4.8 & 0.952 & 94.248 \\
\hline
\end{tabular}

\section{Results and Discussion}

\subsection{Scanning Electron Microscope (SEM)}

Figure 1 shows the surface as well as cross-sectional images of different compositions of the synthesized membranes. It is clear that the porosity of the membranes increased with the increase in filler loading. Clear pores can be seen in all the images of the cross-sectional view, and the dispersion of the filler can be observed in the surface images. The images of the membranes show that the filler was uniformly distributed over the membranes. The cross-section images show the small pores in the membrane that allow $\mathrm{CO}_{2}$ to pass through. 


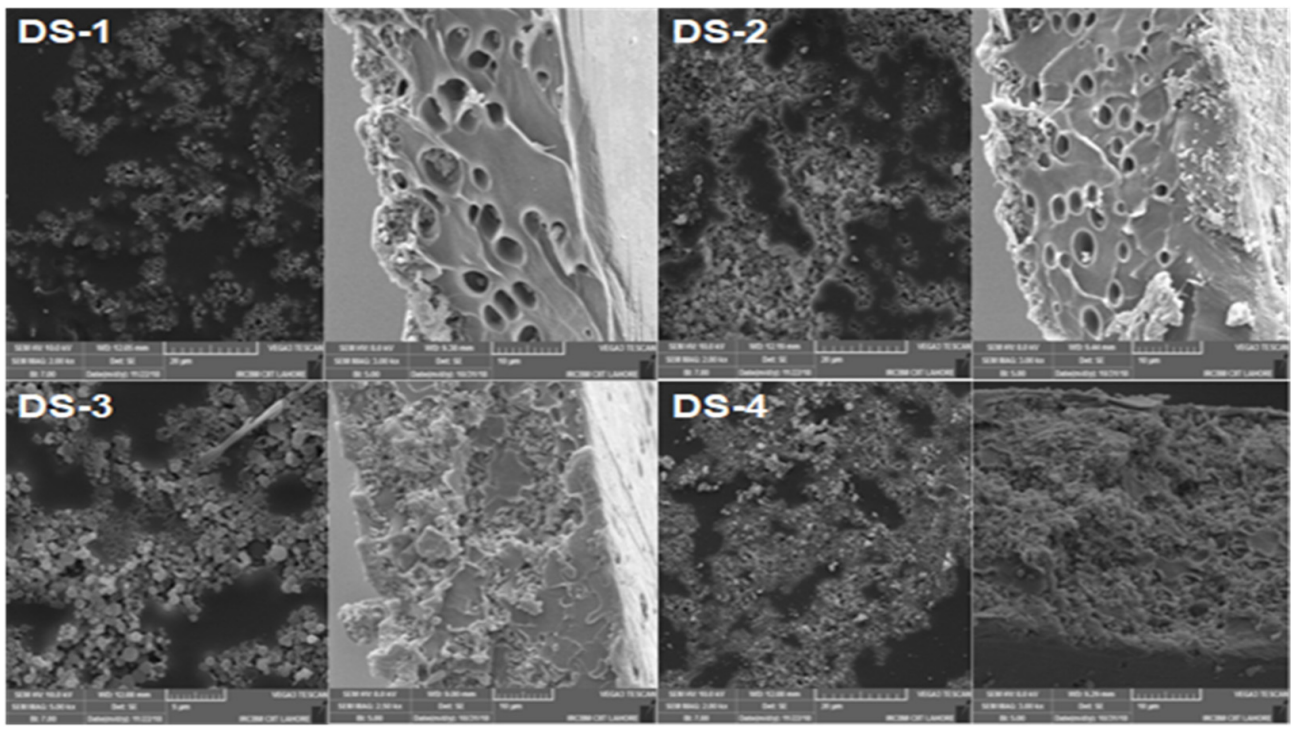

Figure 1. Surface and cross-sectional morphology of synthesized MMMs.

\subsection{Fourier Transform Infrared Spectroscopy (FTIR)}

Figure 2 shows FTIR spectra for SBA-15, DES-SBA, PSF, and the DES-SBA-based synthesized MMMs of different filler loadings. In the figure, the characteristic peaks of polysulfone are suppressed with the increase in filler loading. This suppression shows the interaction of the filler with the polymer, i.e., PSF. Additionally, the characteristic peaks of mesoporous silica are also merged among these peaks of PSF.

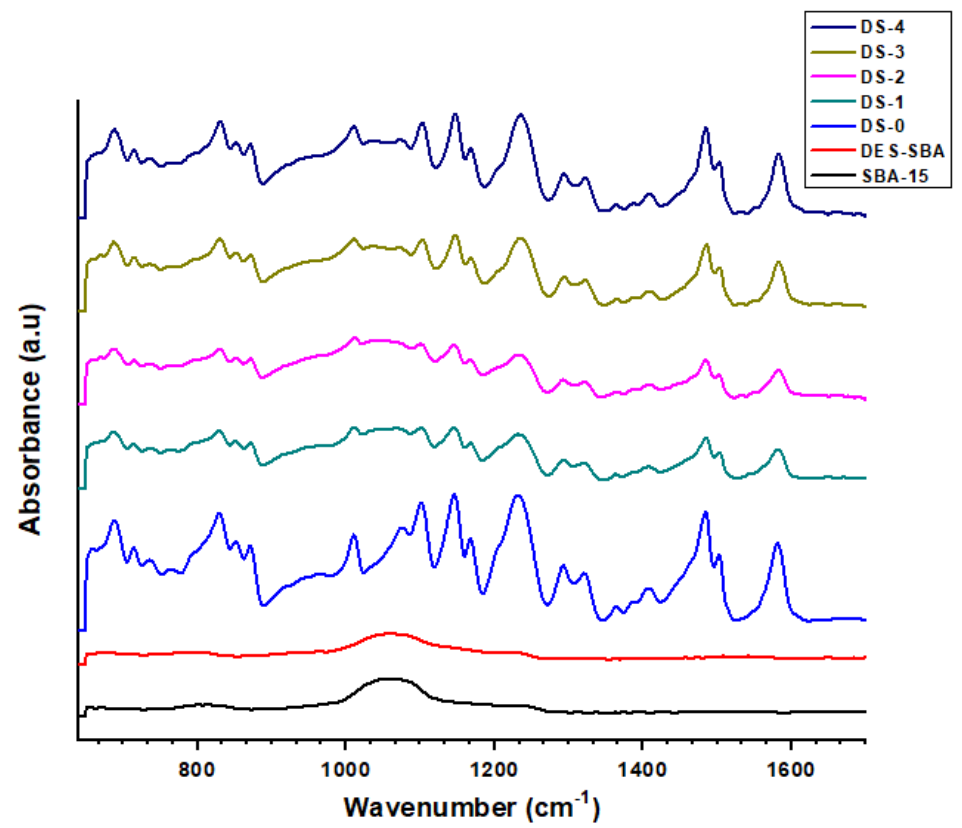

Figure 2. FTIR spectra of SBA-15, DES-SBA, and the synthesized MMMs.

\subsection{Gas Permeation Analysis}

Gas permeation analysis was performed to evaluate the permeability of $\mathrm{CO}_{2}$ and the relative selectivities of the synthesized MMMs at room temperature and 10 bar pressure; the findings can be seen in Figure $3 a, b$. The permeability of the pure PSF membrane DS-0 was 6.06 barrers, and it was increased upto 22.3 barrers by using the $20 \%$ filler in the DS- 4 membrane. The permeability of $\mathrm{CO}_{2}$ was enhanced with the addition of the DES-SBA filler and gradually increased by increasing the filler loading, which refers to the fundamental 
characteristic of DES-SBA, which leads to the fact that the filler has specific pores to provide passage for the selective gas. The selectivity of the mixed gas pairs $\mathrm{CO}_{2} / \mathrm{CH}_{4}$ and $\mathrm{CO}_{2} / \mathrm{N}_{2}$ was also increased with the increase in filler loading, and a very large difference was reported in comparison with the pure PSF membrane DS-0. In the case of $\mathrm{CO}_{2} / \mathrm{CH}_{4}$, the selectivity of DS-0 was 23.31, and it was gradually increased upto 57.18 for DS-4; in the case of $\mathrm{CO}_{2} / \mathrm{N}_{2}$, the selectivity of DS-0 was 25.44 , and it was gradually increased upto 59.9 for DS-4. This increase in the selectivities of the MMMs refers to the strong interaction between the DES-SBA filler and the polymer. The increasing concentration of the DES-SBA filler in the polymeric complex allowed the molecules of the gas to diffuse into the pores of the MMMs following the mesoporous channel, resulting in the high performance of $\mathrm{CO}_{2}$ mitigation from the mixed gases. Hence, the permeation evaluation highly supports the hypothesis of this study.

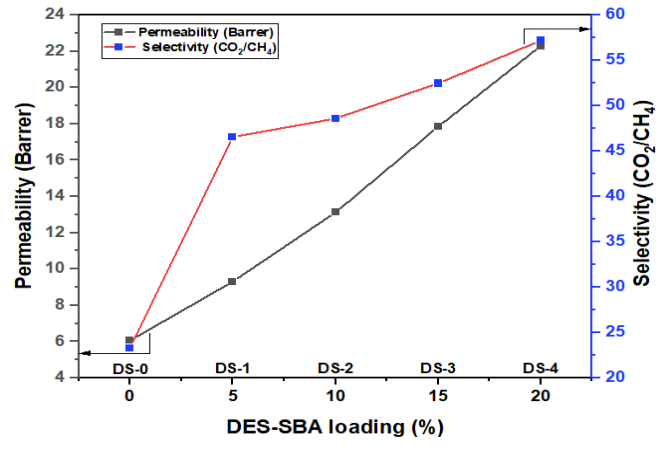

(a)

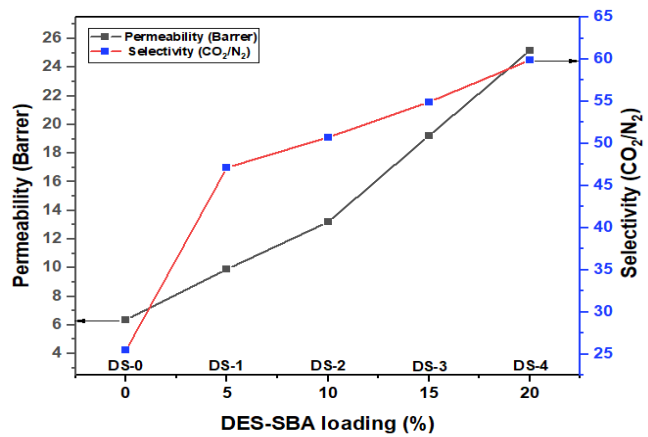

(b)

Figure 3. Gas permeation analysis: (a) permeabilities and selectivities of synthesized $\mathrm{MMMs}$ for $\mathrm{CO}_{2} / \mathrm{CH}_{4}$ gas mixture; (b) permeabilities and selectivities of synthesized $M M M s$ for $\mathrm{CO}_{2} / \mathrm{N}_{2}$ gas mixture.

\section{Conclusions}

This study focused on the synthesis of a choline chloride and decanoic acid-based DES and functionalization of SBA- 15 by the DES to form a DES-SBA filler. MMMs at $5 \%, 10 \%$, $15 \%$, and $20 \%$ filler loadings were fabricated via a casting solution technique. The MMMs were characterized by SEM and FTIR. The gas permeation study was performed in terms of the permeability and selectivity of the MMMs. In the case of the $\mathrm{CO}_{2} / \mathrm{CH}_{4}$ mixed gas, the maximum permeability of $\mathrm{CO}_{2}$ at $20 \%$ filler loading was 22.3 barrers, and the maximum selectivity was 57.18; in the case of the $\mathrm{CO}_{2} / \mathrm{N}_{2}$ mixed gas, the maximum permeability and selectivity were 25.16 barrers and 59.9 , respectively. Thus, the results show the defect-free mechanism of membrane synthesis, and it is concluded that the DES-SBA-based MMMs are potential candidates for $\mathrm{CO}_{2}$ mitigation from mixtures of gases.

\section{References}

1. Cavenati, S.; Cavenati, S.; Grande, C.A.; Rodrigues, A.E. Removal of carbon dioxide from natural gas by vacuum pressures wing adsorption. Energy Fuels 2006, 20, 2648-2659. [CrossRef]

2. Zhang, Y.; Sunarso, J.; Liu, S.; Wang, R. Current status and development of membranes for CO2/CH4 separation:A review. Int. J. Greenh. Gas Control 2013, 12, 84-107. [CrossRef]

3. Houghton, J.T.; Ding, Y.; Griggs, D.J.; Noguer, M. Climate Change 2001: The Scientific Basis; The Press Syndicate of the University of Cambridge: New York, NY, USA, 2001.

4. Koros, W.J.; Mahajan, R. Pushing the limits on possibilities for large scale gas separation: Which strategies? J. Membr. Sci. 2000, 175, 181-196. [CrossRef]

5. Basu, S.; Khan, A.L.; Cano-Odena, A.; Liu, C.; Vankelecom, I.F. Membrane-based technologies for biogas separations. Chem. Soc. Rev. 2010, 39, 750-768. [CrossRef] [PubMed]

6. Burleigh, M.C.; Markowitz, M.A.; Spector, M.S.; Gaber, B.P. Direct synthesis of periodic mesoporous organosilic as: Functional incorporation by co-condensation with organosilanes. J. Phys. Chem. B 2001, 105, 9935-9942. [CrossRef] 
7. Zhao, D.; Huo, Q.; Feng, J.; Chmelka, B.F.; Stucky, G.D. Nonionic triblock and star diblock copolymer and oligomeric surfactantsynthesis of highly ordered, hydrothermally stable, mesoporous silica structures. J. Am. Chem. Soc. 1998, 120, 6024-6036. [CrossRef]

8. Rehman, F.; Volpe, P.L.; Airoldi, C. The applicability of ordered mesoporous SBA-15 and its hydrophobic glutaraldehyde-bridge derivative to improve ibuprofen-loading in releasing system. Colloids Surf. B: Biointerfaces 2014, 119, 82-89. [CrossRef] [PubMed]

9. Shahbaz, K.; Mjalli, F.S.; Hashim, M.A.; AlNashef, I.M. Using deep eutectic solvents based on methyltriphenyl phosphunium bromide for the removal of glycerol from palm-oil-based biodiesel. Energy Fuels 2011, 25, 2671-2678. [CrossRef]

10. Durand, E.; Lecomte, J.; Villeneuve, P. Deep eutectic solvents: Synthesis, application, and focus on lipase-catalyzed reactions. Eur. J. Lipid Sci. Technol. 2013, 115, 379-385. [CrossRef]

11. Saqib, S.; Rafiq, S.; Muhammad, N.; Khan, A.L.; Mukhtar, A.; Mellon, N.B.; Jamil, F. Influence of interfaciall ayer parameters on gas transport properties through modeling approach in MWCNTs based mixed matrix composite membranes. Chem. Eng. Sci. 2020, 218, 115543. [CrossRef] 